\title{
WYKAZ DRUKOWANYCH PRAC KS. PROF. DRA HAB. FRANCISZKA DRĄCZKOWSKIEGO
}

\author{
A. Książki \\ 1. Agape w pismach Klemensa Aleksandryjskiego, Pelplin - Lublin 1980. \\ 2. Kościót-Agape wedtug Klemensa Aleksandryjskiego, Lublin 1983. \\ 3. Miłość synteza chrześcijaństwa, Lublin 1990. \\ 4. Miłość syntezą chrześcijaństwa, Lublin $1991^{2}$ (wydanie poszerzone). \\ 5. Do Boga, który uwesela, Lublin 1993. \\ 6. Gott ist die Liebe. Eine patristische Studie, Lublin 1993. \\ 7. Patrologia. Czesść pierwsza, Toruń 1996. \\ 8. Poza miłościa nie ma zbawienia, Pelplin - Toruń 1996. \\ 9. Miłość-Agape synteza chrześcijaństwa, Pelplin - Toruń 1997. \\ 10. La salvezza e nell' amore, Roma 1998 [Francesco Di Fordon]. \\ 11. Patrologia, Pelplin - Lublin 1998, 1999, 2001, 2009. \\ 12. Piękno prawdziwe. Konferencje radiowe, Pelplin 1998. \\ 13. Pokój serca. Konferencje radiowe, Pelplin 1999. \\ 14. ABC pisania pracy magisterskiej, Pelplin 2000. \\ 15. Błogosławieni znaczy szczéśliwi. Konferencje radiowe, Pelplin 2000. \\ 16. Nowa wizja teologii. Ujęcie graficzne, Pelplin - Lublin 2000. \\ 17. Metoda wykresograficzna w katechezie, Pelplin 2001. \\ 18. Chorzy i cierpiacy ,, arystokracja”” Pana Boga, Pelplin 2001 [współautorstwo \\ z S. Baron]. \\ 19. Skrót katechizmu w ujęciu graficznym, Lublin - Sandomierz 2002. \\ 20. Niebo i piekło zaczyna się na ziemi. Radio „Maryja” Rozmowy niedokończone, \\ Sandomierz 2002. \\ 21. Teologia $w$ kategoriach geometryczno-matematycznych, Pelplin 2003. \\ 22. Die Theologie in geometrischer Darstellung, Lublin 2004. \\ 23. Przyjaźń z Bogiem źródłem szczęścia, Pelplin 2004. \\ 24. Supernatural Geometry, Lublin 2004. \\ 25. Nasze powołanie do szczęścia, Pelplin 2005. \\ 26. Dzięki składajmy Panu Bogu naszemu. Zbiór konferencji wygłoszonych w Radiu \\ Maryja, Lublin 2006. \\ 27. Für Gott ist nichts möglich, Pelplin 2007 [Francesco di Fordon]. \\ 28. Poza Kościołem nie ma zbawienia. Ujęcie graficzne, Pelplin 2008. \\ 29. Rekolekcje w Sierakowicach, Pelplin 2009. \\ 30. Będę na wieki sławit łaski Pana. Autobiografia, Pelplin 2010. \\ 31. Von den Taten deiner Huld, Herr, will ich ewig singens. Autobiographie, Leipzig \\ 2010. \\ 32. Dogmatyka w obrazach graficznych. Zagadnienia wybrane, Pelplin 2011. \\ 33. Patrologia, Pelplin - Lublin $2012^{5}$ (Wydanie poszerzone $\mathrm{z}$ indeksami). \\ 34. Aby radość wasza była petna. Konferencje radiowe, Pelplin 2012.
}


35. Geometryczna struktura teologii, Pelplin 2012.

36. Synteza teologii w ujęciu graficznym, Pelplin 2012.

37. Synthese der Theologie in grafischer Darstellung, Leipzig 2013.

38. Sakramentologia patrystyczna $w$ zarysie, Pelplin 2014.

39. Synteza teologii w ujęciu graficznym, Pelplin $2012^{2}$ (wydanie poszerzone).

40. W Chrystusie petnia szczęścia jedynego. Zbiór konferencji wygłoszonych w Radiu Maryja, Pelplin 2014.

\section{B. Redakcje książek}

1. Wczesnochrześcijańska asceza. Zagadnienia wybrane, red. F. Drączkowski J. Pałucki, Lublin 1993.

2. Ewangelizacja w epoce patrystycznej. Zagadnienia wybrane, red. F. Drączkowski - J. Pałucki, Lublin 1994.

3. Godność chrześcijanina w nauczaniu Ojców Kościoła, red. F. Drączkowski J. Pałucki, Lublin 1996.

4. Droga doskonalenia chrześcijańskiego w epoce patrystycznej. Zagadnienia wybrane, red. F. Drączkowski - J. Pałucki - M. Szram, Lublin 1997.

5. Ojcowie Kościoła wobec filozofii i kultury klasycznej. Zagadnienia wybrane, red. F. Drączkowski - J. Pałucki - M. Szram, Lublin 1998.

6. Kościól starożytny - Królestwo Chrystusa i instytucja, red. F. Drączkowski i inni, Lublin 2010.

7. Katechumenat i inicjacja chrześcijańska w Kościele starożytnym, red. F. Drączkowski i inni, Lublin 2011.

8. Ortodoksja, herezja, schizma w kościele starożytnym, red. F. Drączkowski i inni, Lublin 2012.

\section{Artykuły}

1. Dowartościowanie kultury intelektualnej przez Klemensa Aleksandryjskiego jako rezultat polemiki antyheretyckiej, SPelp 5 (1975) 177-199.

2. Niektóre tendencje i zasady pierwszych wspólnot heterodoksyjnych na podstawie „,Stromatów” Klemensa Aleksandryjskiego”, RTK 23 (1976) z. 4, 55-84.

3. Aktualny stan badań nad Klemensem Aleksandryjskim, CT 3 (1978) 175-177.

4. Formy i zasady pierwszych wspólnot chrześcijańskich na podstawie „Stromatów” Klemensa Aleksandryjskiego, RTK 25 (1978) z. 4, 7-10.

5. Struktury semantyczne wyrazu paideia $w$,, Stromateis” Klemensa Aleksandryjskiego, w: Z zagadnień literatury greckiej, red. J. Pliszczyńska, Lublin 1978, 127-151.

6. Kerygmat pisemny $w$ teorii i praktyce Klemensa Aleksandryjskiego, RTK 26 (1979) z. 6, 21-43.

7. Klemens Aleksandryjski - pedagog oświeconych, AK 93 (1979) 27-36.

8. Wychowawcza funkcja Prawa Starego Testamentu w koncepcji Klemensa Aleksandryjskiego, RTK 26 (1979) z. 3, 17-36.

9. Agape istota chrześcijaństwa wedtug Klemensa Aleksandryjskiego, SPelp 11 (1980) 101-127.

10. Miejsce i rola bojaźni Bożej ( jańskiej wedtug Klemensa Aleksandryjskiego, RTK 27 (1980) z. 3, 21-30. 
11. Qua paideia Clemens Alexandrinus imbutus appareat in animadvertenda falsa gnosi, SACh 2 (1980) 37-83.

12. Kościół jako szkoła Logosu $w$ doktrynie Klemensa Aleksandryjskiego, RTK 28 (1981) z. 4, 137-143.

13. Znaczenie słów Klemensa Aleksandryjskiego „,modlitwa jest rozmowa z Bogiem” w ich kontekście bliższym i dalszym, TST 8 (1981) 129-132.

14. Formy i cele modlitwy doskonałego chrześcijanina (gnostyka) wedtug Klemensa Aleksandryjskiego, w: Medytacja, red. W. Słomka, Homo Meditans 1, Lublin 1983, 127-132.

15. Idee pedagogiczne Klemensa Aleksandryjskiego, VoxP 3 (1983) t. 4, 64-80.

16. Motywacja czynnej miłości bliźniego u Klemensa z Aleksandrii, w: Medytacja, red. W. Słomka, Homo Meditans 1, Lublin 1983, 133-147.

17. Zagadnienie medytacji w nauce Ojców Kościoła, w: Medytacja, red. W. Słomka, Homo Meditans 1, Lublin 1983, 55-81.

18. Szkic chrystologii Klemensa Aleksandryjskiego w świetle onomastyki I księgi „Pedagoga”, VoxP 4 (1984) t. 6-7, 101-125.

19. Trynitarny wymiar miłości chrześcijańskiej w przekazach biblijno-patrystycznych, RTK 31 (1984) z. 4, 43-54.

20. Rewaloryzacja idei postów w nauczaniu Ojców Kościoła, w: Asceza odczłowieczenie czy uczłowieczenie, red. W. Słomka, Homo Meditans 3, Lublin 1985, 125-136.

21. Świętość matżeństwa i rodziny wedtug Klemensa Aleksandryjskiego, VoxP 5 (1985) t. 8-9, 95-125.

22. Termin ,eucharystia” w pismach Klemensa Aleksandryjskiego, VoxP 7 (1987) t. $12-13,73-86$.

23. Chrześcijanie wobec kultury i cywilizacji grecko-rzymskiej. Stanowisko Klemensa Aleksandryjskiego, w: Chrześcijanie a życie publiczne w Cesarstwie Rzymskim III-IV w., red. J. Śrutwa, Lublin 1988, 33-62.

24. „Miłować Boga całym umysłem” w interpretacji Klemensa Aleksandryjskiego, VoxP 8 (1988) t. 15, 603-620.

25. Posty a miłość chrześcijańska w przepowiadaniu Leona Wielkiego, w: Historia i Logos, red. K. Macheta - K. Góźdź - M. Kowalczyk, Lublin 1991, 130-136.

26. Cierpienie i śmierć w nauce Ojców Kościoła, w: Cierpienie i śmierć, red. A.J. Nowak, Homo Meditans 13, Lublin 1992, 29-48.

27. Eucharystia - nieustanne dziękczynienie wedtug Klemensa Aleksandryjskiego, w: Eucharystia - miłość i dziękczynienie, red. W. Słomka - A.J. Nowak, Homo Meditans 9, Lublin 1992, 43-51.

28. Miłość istota chrześcijaństwa i miara człowieczeństwa, w: Być chrześcijaninem dziś. Teologia dla szkół średnich, red. M. Rusecki, Lublin 1992, 591-616.

29. Errori di base nell'esegesi eterodossa secondo l'insegnamento di Clemente Alessandrino, w: Esgesi e catechesi nei Padri (sec. II-IV), a cura di S. Felici, Biblioteca di Scienze Religiose 106, Roma 1993, 97-106.

30. Koncepcja miłości chrześcijańskiej w przekazach biblijno-patrystycznych, w: Miłość w postawie ludzkiej, red. W. Słomka, Homo Meditans 8, Lublin 1993, 117-136.

31. Idea kerygmatu pisemnego $w$ przekazach patrystycznych, w: Ewangelizacja w epoce patrystycznej. Zagadnienia wybrane, red. F. Drączkowski - J. Pałucki, Lublin 1994, 9-20. 
32. Filantropia $(\varphi \imath \lambda \alpha \nu \theta \rho \omega \pi i \alpha)$ - Humanitaryzm chrześcijański wedtug Klemensa Aleksandryjskiego, RTK 43 (1996) z. 4, 75-86.

33. Gnoza w ujęciu Klemensa Aleksandryjskiego, SACh 12 (1996) 9-21.

34. Podstawowe błędy heterodoksyjnej egzegezy Pisma św. wedtug Klemensa z Aleksandrii, SPelp 24 (1996) 129-137.

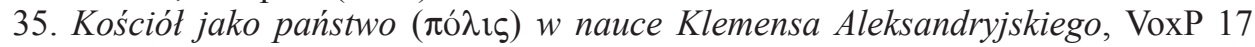
(1997) t. 32-33, 35-43.

36. Święty Leon Wielki Apostołem dobroczynności, w: Mistrz i Przyjaciel. Księga Pamiątkowa ku czci Księdza Profesora Marka Tomasza Zahajkiewicza, red. J. Pałucki, Lublin 1997, 207-218.

37. Kerygmat pisany w nauce Ojców Kościoła, „Anamnesis. Biuletyn Komisji Kultu Bożego i Dyscypliny Sakramentów Episkopatu Polski” 16 (1998/1999) z. 1, 4254.

38. Antynestoriańska teologia wcielenia Cyryla Jerozolimskiego, VoxP 20 (2000) t. 38-39, 259-266.

39. Keryks słowa pisanego, w: Diligis Me? Pasce. Księga jubileuszowa dedykowana Biskupowi Sandomierskiemu Wacławowi Józefowi Świerzawskiemu na pięćdziesięciolecie święceń kapłańskich 1949-1999, red. S. Czerwik - M. Mierzwa - R. Majkowska, t. 2, Sandomierz 2000, 27-33.

40. Modlitwa - ,nieustanne przebywanie z Bogiem”-wświetle przekazów patrystycznych, w: Homo Orans, red. J. Misiurek - J.M. Popławski, t. 1, Lublin 2000, 69-85.

41. Informacja $w$ stużbie kerygmatu, „Anamnesis. Biuletyn Komisji Kultu Bożego i Dyscypliny Sakramentów Episkopatu Polski” 24 (2001) z. 1, 30-42.

42. Uniwersalny wymiar kerygmatu wczesnochrześcijańskiego, „Theologica Thorunensia" 2 (2001) 5-21.

43. Wartość ,'świadectwa krwi” wedtug Klemensa Aleksandryjskiego, w: Kościót $i$ historia. Drogi $i$ wzajemne powiązania. Księga pamiątkowa ku czci Księdza Profesora Anzelma Weissa, red. S. Tylus - J. Walkusz, Lublin 2001, 89-98.

44. Jezus Chrystus Zbawiciel w pismach Klemensa Aleksandryjskiego, w: Ku prawdzie w miłości. Księga pamiątkowa poświęcona Księdzu Biskupowi Profesorowi Janowi Śrutwie, red. S. Koczwara, Lublin 2002, 43-61.

45. Powszechność funkcji keryksa w Kościele starożytnym. Stanowisko Klemensa Aleksandryjskiego, VoxP 22 (2002) t. 42-43, 101-117.

46. Rodzaje świadczenia Chrystusowi w nauce Klemensa Aleksandryjskiego, SPelp 33 (2002) 209-218.

47. Miłość bliźniego $w$ świetle ekshortacji pastoralnych Leona Wielkiego $w$ mowach na Wielki Post (39-50), VoxP 24 (2004) t. 46-47, 527-536.

48. Metoda wykresograficzna (geometryczna) w kontekście współczesnego zagrożenia herezjami, w: Lumen Christi tantum in Ecclesia. Księga pamiatkowa w 70. rocznice urodzin o. Prof. dr. hab. Antoniego Jozafata Nowaka OFM, red. T. Paszkowska, Lublin 2005, 285-304.

49. Miłość synteza chrześcijaństwa, w: Dobroczynna postuga Kościoła, red. M. Marczewski, Lublin 2005, 173-200.

50. Nowa metoda w teologii i duszpasterstwie, w: W stużbie Bogu i ludziom. Ksiega pamiątkowa poświęcona ks. prof. dr. hab. Władysławowi Głowie z okazji 65-lecia urodzin i 40-lecia kapłaństwa, red. H. Słotwińska, Lublin 2005, 111-122. 
51. Definicja miłości chrześcijańskiej Klemensa Aleksandryjskiego w świetle encykliki Benedykta XVI „Deus caritas est”, VoxP 26 (2006) t. 49, 145-165.

52. Duchowy charakter królestwa Bożego w świetle przekazów patrystycznych, w: Historia świadectwem czasów. Księga pamiatkowa poświęcona Księdzu Profesorowi Markowi Tomaszowi Zahajkiewiczowi, red. W. Bielak - S. Tylus, Lublin 2006, 191-201.

53. Metoda geometryczna (wykresograficzna) w teologii, RT 53 (2006) z. 4, 21-43.

54. Metoda wykresograficzna w katechezie, w: W poszukiwaniu nowych metod katechetycznych, red. H. Słotwińska, Lublin 2006, 89-133.

55. Ideał kapłaństwa w pismach Klemensa Aleksandryjskiego, VV 12 (2007) 141-146.

56. Il metodo disegno-grafico nella catechesi, „Angelicum” 84 (2007) 317-341.

57. Motywacja odkrywania świętości najlepsza droga do szczęścia na podstawie pism Ojców Greckich, AK 149 (2007) z. 2 (591), 241-251.

58. Priorytet formacji intelektualno-moralnej $w$ świetle wybranych przekazów biblijno-patrystycznych, „Pedagogika katolicka” 1a (2007) 38-49.

59. Patrystyczna wizja pedagogiki katolickiej, w: Kierunki pedagogiki katolickiej, red. J. Zimny, Stalowa Wola 2008, 85-106.

60. Pedagogia Boża w pismach Ojców Kościoła, VoxP 28 (2008) t. 52/1, 137-156.

61. Program formacji integralnej w świetle „Homilii na Ewangelie” św. Grzegorza Wielkiego, w: Lectio divina, red. J.M. Popławski, Homo Meditans 29, Lublin 2008, 53-74.

62. Koncepcja wychowania chrześcijańskiego w ujęciu Klemensa Aleksandryjskiego oraz Jana Chryzostoma, VoxP 29 (2009) t. 53-54, 313-327.

63. Zagrożenie błędnowierstwa i herezji w Kościele współczesnym, w: In Persona Christi. Księga na 80-lecie Księdza Profesora Czesława S. Bartnika, red. K. Góźdź, Lublin 2009, 535-542.

64. Agapetyczna struktura Kościoła w świetle przekazów patrystycznych, w: Ojcowie Kościoła w trosce o życie duchowe człowieka, red. J. Przeździecki - T. Styczewski - S. Mazur, Drohiczyn 2010, 9-27.

65. Eklezjologia Klemensa Aleksandryjskiego, w: Kościót starożytny - Królestwo Chrystusa i instytucja, red. F. Drączkowski i inni, Lublin 2010, 51-75.

66. Obowiazki i przywileje ludzi starszych wedtug Klemensa Aleksandryjskiego, VoxP 31 (2011) t. 56, 281-297.

67. Wczesnochrześcijańskie świadectwa o karmieniu się Eucharystia, w: Eucharystia - dar uzdalniajacy do czynienia daru z siebie. Materiaty z dziewiątego Sympozjum Liturgicznego Diecezji Siedleckiej, Siedlce 26 listopada 2011 roku, red. I. Chłopkowska, Warszawa - Siedlce 2012, 24-54.

\section{Hasła encyklopedyczne i słownikowe}

1. Bage, EK I 1257.

2. Bagnoregio, EK I 1258.

3. Barranca Barmeja, EK II 62.

4. Barranquilla, EK II 62.

5. Bucaramanga, EK II 1144.

6. Dafne, EK II 969-970.

7. Dekster, EK II 1122. 
8. Delfy, EK III 1129-1130.

9. Demeter, EK III 1142-1144.

10. Dezydery, EK III 1230.

11. Dhimmi, EK III 1238.

12. Diatessaron, EK III 1296-1297.

13. Didaskalia apostolskie, EK III 1303-1304.

14. Dionizos, EK III 1334-1336 [współautorstwo z E. Zwolski].

15. Dionizy Bar Salibi, EK III 1339.

16. Dionizy Maty, EK III 1340-1341.

17. Dioskur papież, EK III 1344.

18. Dioskur patriarcha, EK III 1343-1344.

19. Doctrina Patrum, EK IV 2-3.

20. Donatyzm, EK IV 111-113.

21. Donus, EK IV 116-117.

22. Drakoncjusz, EK IV 183.

23. Dydym Slepy, EK IV 414-415.

24. Dyktyniusz z Astorgii, EK IV 416-417.

25. Dziech Józef, EK IV 464.

26. Efrem, EK IV 681-683.

27. Egbert z Yorku, EK IV 686.

28. Ekumeniusz, EK IV 852-853.

29. Eliasz, EK IV 888.

30. Elipidiusz Rustyk, EK IV 902.

31. Elwira, EK IV 906-907.

32. Enaniszo, EK IV 982.

33. Ennodiusz; EK IV 1009-1010.

34. Epidauros, EK IV 1019-1020.

35. Epifaniusz, EK IV 1021-1023.

36. Epitoma, EK IV 1054.

37. Eros, EK IV 1094-1095.

38. Eucheriusz, EK IV 1283-1284.

39. Eugeniusz II (III), EK IV 1293-1294.

40. Eusebius Gallinacus, EK IV 1339.

41. Eutropiusz, EK IV 1346.

42. Eutropiusz Prezbiter, EK IV 1347.

43. Euzebiusz z Cezarei, EK IV 1351-1355.

44. Euzebiusz z Doryleum, EK IV 1355.

45. Euzebiusz z Samosat; EK IV 1356-1357.

46. Ewagriusz z Antiochii, EK IV 1372.

47. Ewagriusz Prezbiter, EK IV 1374.

48. Fakund, EK V 18.

49. Fastydiusz, EK V 63.

50. Faust z Bizancjum, EK V 78-79.

51. Faust z Riez, EK V 79-80.

52. Faustyn, EK V 81.

53. Febadiusz, EK V 83. 
54. Felicysym, EK V 103-104.

55. Feliks III (II), EK V 107.

56. Feliks IV (III), EK V 107-108.

57. Ferreol, EK V 143.

58. Filaster, EK V 192-193.

59. Fileas, EK V 194.

60. Filetos Gnostyk, EK V 194.

61. Filip, EK V 199.

62. Filip Arab; EK V 204.

63. Filip Prezbiter, EK V 207.

64. Filip z Side, EK V 208.

65. Filokalia, EK V 230-232 [współautorstwo z B. Modzelewska].

66. Filoksen, EK V 232.

67. Filon z Aleksandrii, EK V 236-239 [współautorstwo z W. Kolecki].

68. Filostorgiusz, EK V 240-241.

69. Firmicus Maternus, EK V 300.

70. Firmus, EK V 301.

71. Flawian I, EK V 323.

72. Florilegium, EK V 344-345.

73. Fociusz Diakon, EK V 360.

74. Fruktuoz, EK V 729.

75. Fulgencjusz z Ruspe, EK V 754-756.

76. Gallandi, EK V 831.

77. Gelazy I, EK V 932.

78. Gelazy z Cezarei, EK V 933.

79. Gennadiusz, EK V 963.

80. German I, EK V 1001-1002.

81. Geroncjusz z Jerozolimy, EK V 1015.

82. Greccy Ojcowie, EK VI 61-64.

83. Grzegorz z Nazjanzu, EK VI 313-316.

84. Grzegorz z Nysy, EK VI 316-320.

85. Hipolit, EK VI 916-918.

86. Hipolita statua, EK VI 919.

87. Ignacy Antiocheński, EK VI 1441-1443.

88. Iluminacja $w$ okresie patrystycznym, EK VII 34-35.

89. Izydor Gnostyk, EK VII 622.

90. Izydor z Sewilli, EK VII 619-621.

91. Jezus Chrystus, IV. Nazwy, 2. Patrystyczne, EK VII 1353-1355.

92. Kerygmat, 2. W przekazach patrystycznych, EK VIII 1362-1363.

93. Klemens Aleksandryjski, EK IX 98-102.

94. Pedagogika Ojców i pisarzy kościelnych, w: Encyklopedia Pedagogiczna XXI wieku, red. T. Plich i inni, t. 4, Warszawa 2005, 88-92.

95. Agape, w: Leksykon teologii pastoralnej, red. R. Kamiński, Lublin 2006, 25-29.

96. Maksym Wyznawca, EK XI 902-905.

97. Miłość, I. Aspekt semantyczny, EK XII 1122-1123.

98. Ojcowie Kościoła, EK XIV 447-448. 


\section{E. Przekłady}

1. List Nestoriusza do Cyryla Aleksandryjskiego, w: Maryja w tajemnicy Chrystusa, red. S.C. Napiórkowski - S. Longosz, Niepokalanów 1997, 227-230.

2. List II Cyryla Aleksandryjskiego do Nestoriusza, w: Maryja w tajemnicy Chrystusa, red. S.C. Napiórkowski - S. Longosz, Niepokalanów 1997, 231-233.

\section{F. Recenzje}

1. E.F. Saner, Benediktsregel und Weltlente, Augustin-Hangelar 1980 - O regule św. Benedykta bez benedyktyńskiej pokory, VoxP 2 (1982) t. 3, 160-168.

2. J. Pałucki, Trynitarny wymiar Kościoła. Studium patrystyczne, Lublin 2007, Wydawnictwo KUL, ss. 320, VoxP 29 (2009) t. 53-54, 691-693.

\section{G. Inne}

1. Spotkanie Sekcji Patrystycznej w Gdańsku-Oliwie, VoxP 4 (1984) t. 6-7, 465-469.

2. Katolicki Uniwersytet Lubelski. Katedra Patrologii, VoxP 8 (1989) t. 16, 367-368.

3. Przedmowa, w: Wczesnochrześcijańska asceza. Zagadnienia wybrane, red. F. Drączkowski - J. Pałucki, Lublin 1993, 5-8.

4. Przedmowa, w: Ewangelizacja w epoce patrystycznej. Zagadnienia wybrane, red. F. Drączkowski - J. Pałucki, Lublin 1994, 5-8.

5. Katedra Patrologii w Katolickim Uniwersytecie Lubelskim (rys historyczny), w: Tysiac imion Chrystusa. Seminarium Patrystyczne KUL 1983-1993, red. J. Pałucki, Lublin 1994, 9-15.

6. Profil organizacyjno-naukowy Seminarium Patrystycznego w KUL (1983-1993), w: Tysiac imion Chrystusa. Seminarium Patrystyczne KUL 1983-1993, red. J. Pałucki, Lublin 1994, 29-43.

7. Przedmowa, w: Godność chrześcijanina w nauczaniu Ojców Kościoła, red. F. Drączkowski - J. Pałucki, Lublin 1996, 3-10.

8. Słowo wstępne, w: Ojcowie Kościoła w Brewiarzu. Indeksy, red. P. Kwiatkowski, Toruń 1997, 5-8.

9. Wstęp, w: Droga doskonalenia chrześcijańskiego w epoce patrystycznej. Zagadnienia wybrane, red. F. Drączkowski - J. Pałucki - M. Szram, Lublin 1997, 3-8.

10. Wstęp, w: Ojcowie Kościoła wobec filozofii i kultury klasycznej. Zagadnienia wybrane, red. F. Drączkowski - J. Pałucki - M. Szram, Lublin 1998, 3-8.

11. Wkład Katedr Patrologii KUL w przybliżanie nauki Ojców Kościoła, VoxP 19 (1999) t. 36-37, 39-51 [współautorstwo z P. Szczur].

12. Święty Augustyn odkrywany przez muzułmanów (Alger-Annaba - Souk-Ahras, 1-7 IV 2001), VoxP 22 (2002) t. 42-43, 772-776.

13. Z kart historii Seminarium Toruńskiego. Relacja pierwszego Rektora, „Theologica Thorunensia" 4 (2003) 13-27.

14. Redaktor naczelny „, Vox Patrum” odznaczony Krzyżem Kawalerskim Orderu Odroczenia Polski, VoxP 22 (2004) t. 46-47, 883-885. 